\title{
Satisfaction Analysis of Cross-border Electricity Merchants in Henan Based on Structural Equation Model
}

\author{
Xiao Tian, Xiaogai Yan* \\ School of Management Engineering, Zhengzhou University, Science Avenue,Zhengzhou,China \\ 1239941849@qq.com,cgtzzu@163.com
}

Keywords: Cross-border e-commerce in Henan, talent satisfaction, structural equation model, influencing factors

\begin{abstract}
Industry dispute is the battle for talent. The vigorous development of cross-border e-commerce in Henan has made the competition between government and enterprises for cross-border e-commerce talents increasingly fierce. The lack of professional talents has become an important factor restricting the development of cross-border e-commerce in Henan. Based on the four dimensions of regional factors, organizational system, personal factors and interpersonal relationship, the paper uses structural equation modeling to explore its influence path and influence degree on Henan cross-border electric merchants' satisfaction. Studies have shown that regional factors, organizational systems, personal factors and interpersonal relationships have a positive impact on talent satisfaction, but the degree of impact is not the same. Finally, different suggestions are proposed from different levels, with a view to improving the satisfaction of cross-border electricity merchants in Henan, thus increasing the competitiveness of Henan cross-border e-commerce industry.
\end{abstract}

\section{Introduction}

With the continuous development of the Internet and Internet of Things technologies and the improvement of the UPU system, China's cross-border e-commerce has gradually emerged as a leap-forward development trend, becoming the most popular way of foreign trade. Since Zhengzhou has been a pilot city for cross-border e-commerce comprehensive pilot zones, the pilot business volume has ranked first in the country for five consecutive years. The export business volume from 2017 to 2018 has increased by 100 times, and the business volume accounted for the national business. At the same time, however, Henan cross-border electricity merchants are in short supply. The shortage of talents has become a bottleneck problem for the development of cross-border e-commerce enterprises in Henan. Whether it is possible to identify the influencing factors affecting the satisfaction of cross-border e-commerce in Henan has become the key to restrict the further development of cross-border e-commerce enterprises in Henan.

At present, a large number of scholars have studied the influencing factors of talent satisfaction. From the perspective of hard environment, Wang Jianqiang believes that personal income is the main factor affecting talent satisfaction(Jianqiang Wang, 2005);From the perspective of soft environment, Cheng Wei believes that leadership management environment, social and human 
environment are the main factors affecting talent satisfaction(Wei, Cheng, 2006); From a macro perspective, Ji Jianyue believes that the level of regional economic development is the main factor affecting talent satisfaction (Jianyue Ji, Yanbin Zhu, 2008); From the perspective of enterprises, Sun Jianmin believes that the development prospects of enterprises are the most important factors affecting talent satisfaction(Jianmin Sun, Hong Jiang, 2010); Guo Honglin et al. From the perspective of personal factors, it is considered that the perception of talents' attitudes toward the personnel department is an important factor affecting their satisfaction(Honglin Guo, Feng Qi, Fan Wang, 2016.); Liu Jun and others based on the perspective of overseas high-end talents, that the level of $R \& D$ investment, children's education conditions, and medical conditions affect talents. The main factor of satisfaction(Jun Liu, Chenyao Qu, Haochang Yang, 2017). It is not difficult to see that the above scholars' research on the factors affecting talent satisfaction has not been separated. Based on this, this paper constructs an index system that affects the satisfaction of cross-border electric merchants in Henan. It hopes to provide theoretical and practical basis for improving the satisfaction of cross-border electric merchants.

\section{Research Hypothesis}

On the basis of analyzing and summarizing the research of all levels of scholars in the past, this paper will discuss the influencing factors of cross-border electric merchants in Henan from four levels, namely regional factors, organizational systems, interpersonal relationships and personal factors, among which regional factors include policy factors, economic factors, social environment and living environment, and thus construct the model shown in Figure 1 below.

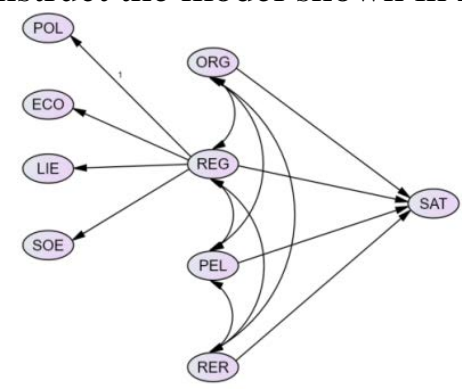

Figure 1 Henan cross-border electricity merchant satisfaction model

\subsection{Regional Factors and Cross-Border Electricity Merchant Satisfaction}

Regional factors are the most direct factors affecting the satisfaction of cross-border electricity merchants. The charming regional environment can give cross-border electricity merchants a good first impression, thus improving talent satisfaction. The loose household registration system can reduce the difficulty of foreign cross-border electric merchants to settle down. In terms of economic factors, among all the factors that affect the satisfaction of talents, the economy factors play a fundamental and decisive role (Weilin Cao,Yijie Wang, Zhiying Liu, 2016). Good economic conditions can provide a better material basis. On this basis, talents are likely to pursue the needs of all levels (Qingxiong Weng, Shuchun Yang, Weilin Cao, 2014). The better the natural environment of a place, the higher the satisfaction of talents in this place (Soete L, 2006). Therefore, we assume that:

H1: Regional factors are positively correlated with cross-border talent satisfaction

\subsection{Organizational System and Talent Satisfaction}

The company's tolerance system, influential cultural values and working atmosphere are the 
factors that have the greatest impact on talent satisfaction (Jing Guo, Xinmin Yuan, 2018). A good organizational environment can dilute other factors that make cross-border e-commerce businessmen dissatisfied and better promote positive factors. Play a role, thereby enhancing the attractiveness of talents and improving the satisfaction of talents (Weilin Cao,Yijie Wang, Zhiying Liu, 2016). A reasonable salary system can satisfy the needs of the lowest level of cross-border electric traders; establish a training system for different positions and employees at different levels to adapt to their own development, so that cross-border electric businessmen can achieve personal growth. Therefore, we assume that:

H2: Organizational system is positively correlated with cross-border electricity merchant satisfaction.

\subsection{Interpersonal Relationship and Cross-Border Electricity Merchant Satisfaction}

People are group animals, and no one can exist in an individual form, so interpersonal relationships are particularly important. Zhang Yujiao proposed that communication environment and interpersonal relationship are one of the factors affecting the job satisfaction of the talents. Dou $\mathrm{Yu}$ has found that friendship opportunities have a positive effect on job satisfaction through hotel research. Friendship universality positively affects organizational commitment. The two dimensions of workplace friendship can significantly reduce the employee's willingness to leave. Organizations with democratic leadership style will delegate their authority to employees, so that employees feel that they are valued. Therefore, we assume that:

H3: Interpersonal relationship is positively related to cross-border e-commerce satisfaction

\subsection{Personal Factors and Cross-Border Electricity Merchant Satisfaction}

Cross-border electricity merchants will perceive the surrounding environment and then form their own psychological expectations. When psychological expectations are good, they will improve their satisfaction. First of all, talents attach great importance to their own development. When they are satisfied with their promotion or through the training courses provided by the organization to make their own learning grow faster, they will increase their positive expectations for their career development prospects, thus enhancing their own satisfaction degree (Jing Guo, Xinmin Yuan, 2018). In addition, when you give full play to your own value by making full use of your knowledge and ability, you will also improve your own satisfaction (Shihong Wei, 2017). Therefore, we assume that:

H4: Personal factors are positively correlated with cross-border e-commerce satisfaction

\section{Study sample and variable measurement}

\subsection{Research Sample}

The study was conducted by employees of cross-border e-commerce companies in Henan Province. A total of 302 questionnaires were distributed and 302 were eventually recovered. The recovery rate was $100 \%$. If the questionnaire answer option is clearly consistent or the answer is incomplete, it is considered invalid and invalidated. Excluding 41 incomplete questionnaires and invalid questionnaires, and 261 remaining valid questionnaires, the effective rate of the questionnaire was $86.4 \%$. 


\subsection{Variable Measurement}

In addition to the basic information, the scales are in the form of five-level scales, ranging from 1 to 5 respectively, indicating "completely disagree" to "completely agree". The organizational system measurement scale is mainly based on the research on the factors affecting the satisfaction of creative talents by Guo Jing and Yuan Xinmin. On the basis of the summary, the main indicators are summarized, and finally the measurement scale of this paper is formed(Jing Guo, Xinmin Yuan, 2018). The interpersonal relationship measurement scale mainly uses Zhang Ling's employee satisfaction scale for Jingdong Mall, and the personal factor measurement scale mainly adopts Wei Shihong. A scale for the impact of incentive systems on the satisfaction of talent in large e-commerce organizations(Shihong Wei, 2017).

The policy factor sub-variables in the regional environment mainly include four items, namely, talent support, household registration management system, innovation incentive policy and talent policy popularization; economic factor sub-variables include three items, namely economic development. Momentum, regional average salary and cross-border e-commerce development prospects; social environment sub-variables include four items, namely natural environment, cost of living, traffic conditions and public security environment; sub-variables of living environment include three items, respectively Educational conditions, medical and health conditions and leisure and entertainment conditions. Cross-border electricity merchant satisfaction is measured mainly by adopting four items such as "I like the place where I work, and I am happy to work and live in the workplace".

\section{Empirical analysis}

\subsection{Reliability and Validity Analysis}

Table 1 Differential validity analysis table

\begin{tabular}{c|c|c|c|c|c|c}
\hline & $\begin{array}{c}\text { Convergence } \\
\text { validity }\end{array}$ & \multicolumn{5}{c}{ Pearson correlation and discriminant validity } \\
\cline { 2 - 7 } & AVE & $\begin{array}{c}\text { Talent } \\
\text { satisfaction }\end{array}$ & $\begin{array}{c}\text { Personal } \\
\text { reason }\end{array}$ & $\begin{array}{c}\text { Interpersonal } \\
\text { relationship }\end{array}$ & $\begin{array}{c}\text { Organizational } \\
\text { system }\end{array}$ & $\begin{array}{c}\text { Regional } \\
\text { factor }\end{array}$ \\
\hline $\begin{array}{c}\text { Talent } \\
\text { satisfaction }\end{array}$ & 0.514 & $\mathbf{0 . 7 1 7}$ & & & & \\
$\begin{array}{c}\text { Personal reason } \\
\text { Interpersonal }\end{array}$ & 0.526 & 0.584 & $\mathbf{0 . 7 2 5}$ & & & \\
$\begin{array}{c}\text { relationship } \\
\text { Organizational } \\
\text { system }\end{array}$ & 0.562 & 0.582 & 0.553 & $\mathbf{0 . 7 5 0}$ & & \\
Regional factor & 0.524 & 0.613 & 0.599 & 0.628 & $\mathbf{0 . 7 2 4}$ & \\
\hline
\end{tabular}

Note: The diagonal line is the root value of AVE, and the lower triangle is the facet Pearson correlation. In summary, the questionnaire has good reliability and validity.

A good measurement model should has good reliability and validity. To ensure the reliability and validity of the measurement model results, this section analyzes the reliability and validity of the data. The overall Cronbach's $\alpha$ coefficient of the questionnaire is 0.933, Cronbach's five sub-variables of "regional factors", "organizational system”, "interpersonal relationship”, "personal factors" and "cross-border electricity merchant satisfaction". The $\alpha$ coefficients are $0.841,0.810$, $0.774,0.844$, and 0.806, respectively, indicating that the internal consistency, stability, and 
reliability of the questionnaire are good. The Std. of each latent variable in this paper is greater than 0.6 , and the SMC is greater than 0.36, indicating that the questionnaire has good topic reliability. Except for the "interpersonal relationship" latent variable CR is 0.790 , which is very close to 0.8 , and the CR of the remaining latent variables are greater than 0.8 , indicating that the various facets of the scale and its observed variables have good combination reliability. The difference validity is shown in Table 1. The root value of AVE indicate that the difference validity of the model is relatively good.

\subsection{Regional Factors Second-Order Verification}

Because regional factors contain many influencing factors, therefore, the second-order model is used to simplify the regional factors.

Firstly, the reliability and validity of the regional factors are tested. The Cronbach's $\alpha$ coefficient value of the economic factor is 0.715 , and the rest are greater than 0.8 . The standardization coefficient Std. in the reliability of the topic is greater than 0.6, and the multivariate correlation SMC is greater than 0.36 . The combined reliability CR is greater than 0.7 , The convergence validity of other factors is greater than 0.5 , and the values are within the ideal range. Has a good reliability and validity. Finally, observe the model fit. As shown in Table 2, the fitness index GFI, CFI, and TLI are all greater than 0.9 , and the RMSEA index is less than 0.08 , which is closer to 0.05 . The second-order verification factor analysis fitting index AGFI is 0.898 , which is very close to 0.9 . The $\chi^{2}$ value of the first-order confirmatory analysis of the regional factor is 127.442 , the $\chi^{2}$ value of the second-order confirmatory analysis is 146.133 , and the target coefficient is 0.872 , which is closer to 1 , which is acceptable. Therefore, it can be explained that regional factor secondary model can replace the first-order model.

Table 2 Regional factor second-order verification model with appropriateness index

\begin{tabular}{c|c|c|c|c|c|c|c|c}
\hline $\begin{array}{c}\text { Regional factor } \\
\text { second-order } \\
\text { verification factor } \\
\text { model }\end{array}$ & $\boldsymbol{\chi 2}$ & $\begin{array}{c}\text { Degree of } \\
\text { freedom } \\
\mathbf{( d f )}\end{array}$ & $\boldsymbol{\chi 2}$ /df & GFI & AGFI & CFI & TLI & RMSEA \\
\hline level one & 127.442 & 71.000 & 1.795 & 0.936 & 0.906 & 0.969 & 0.961 & 0.055 \\
Second order & 146.133 & 73.000 & 2.002 & 0.929 & 0.898 & 0.960 & 0.950 & 0.062 \\
\hline
\end{tabular}

\subsection{Model Fitting}

From the above analysis, it is known that the model shown in Figure 2 is finally established:

As shown in the figure, the goodness of fit index GFI is 0.843 , and the AGFI is 0.813 . The comparison fit index CFI is 0.912, the Tuck-Lewis index TLI (NNFI) is 0.902, and the values are all greater than 0.9 , which is very desirable. In terms of the defect index: the approximate error root mean square RESEM is 0.058 , its value is less than the acceptable value of 0.08 , and is closer to the ideal value of 0.05 . Therefore, it can be explained that the final overall e-commerce talent satisfaction model can reflect the measured sample variable data and has a good fitness.

Henan cross-border e-commerce talent satisfaction model research hypothesis path coefficient and its significant relationship as shown in Table 3, overall, the standardization coefficient of each path relationship is positive, The path coefficient of regional factors for e-commerce talent satisfaction is 0.190 , and the P value is 0.023 . Therefore, the research hypothesis $\mathrm{H} 1$ is established. The path coefficient of organizational system to e-commerce talent satisfaction For 0.225 , the $\mathrm{P}$ value is 0.026 , so the study assumes that $\mathrm{H} 2$ is established; the path coefficient of interpersonal 
relationship factors for e-commerce talent satisfaction is 0.242 , $\mathrm{P}$ value is 0.010 , so research Assume that $\mathrm{H} 3$ is established; the path coefficient of personal factors for e-commerce talent satisfaction is 0.211 , P value is 0.018 , so the research hypothesis H4 is established.

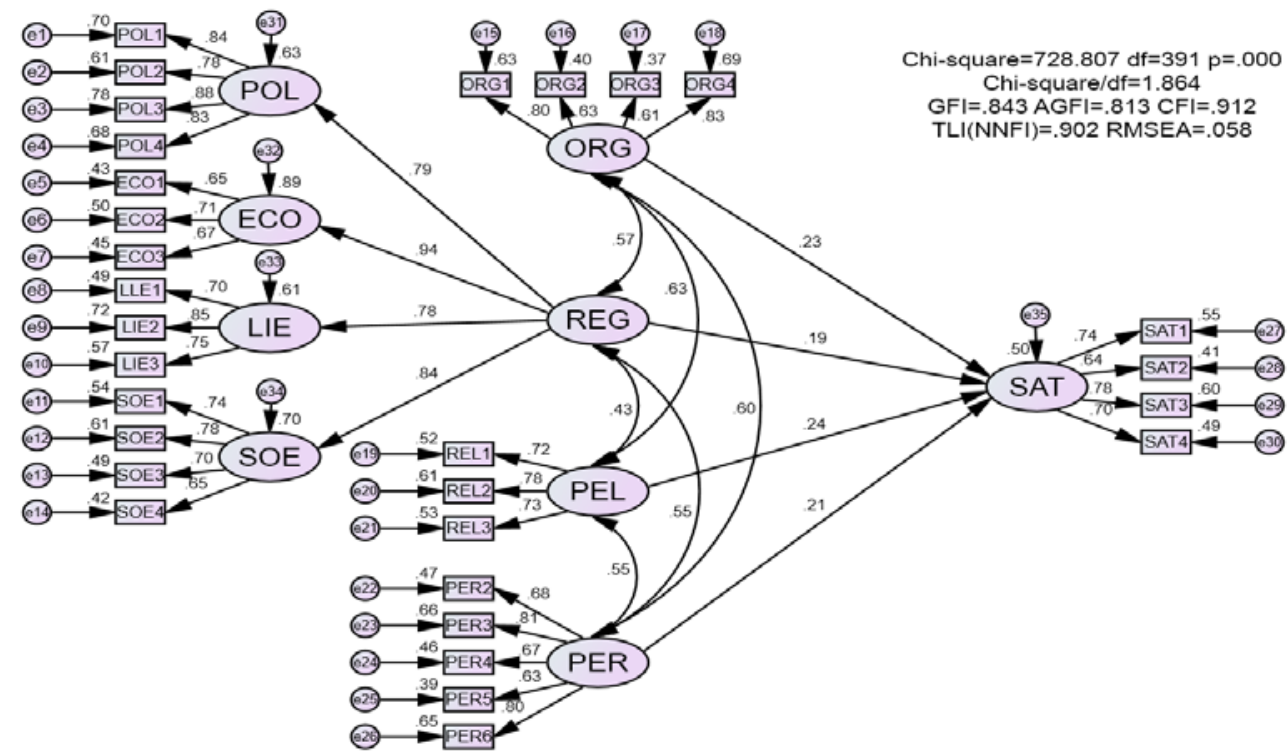

Figure 2 The final model of cross-border e-commerce talent satisfaction

Henan cross-border e-commerce talent satisfaction model research hypothesis path coefficient and its significant relationship as shown in Table 3:

Table 3 Study hypothesis path coefficient graph

\begin{tabular}{c|c|c|c|c|c}
\hline Path relationship & Non-standar-dized & S.E. & CR & P & Standardization \\
\hline $\begin{array}{c}\text { Talent Satisfaction } \\
\text { <---Organization System } \\
\begin{array}{c}\text { Talent satisfaction } \\
\text { <---regional factors }\end{array}\end{array}$ & 0.182 & 0.082 & 2.228 & 0.026 & 0.225 \\
$\begin{array}{c}\text { Talent Satisfaction } \\
\text { <---Interpersonal Relationship } \\
\text { Talent satisfaction } \\
\text { <---personal factors }\end{array}$ & 0.180 & 0.079 & 2.276 & 0.023 & 0.190 \\
\hline
\end{tabular}

\section{Research conclusions and recommendations}

Through the path analysis and significant analysis of the e-commerce talent satisfaction research hypothesis, regional factors, organizational systems, interpersonal relationships and personal factors have a positive impact on e-commerce talent satisfaction. The path coefficients of each factor are not much different, indicating that each factor is very important for talent satisfaction.

First, interpersonal relationships have the greatest impact on cross-border e-commerce talent satisfaction. For the company's leaders, the first is to strengthen communication with cross-border e-commerce talents; the second is to fully trust cross-border electric businessmen. For cross-border electric businessmen themselves, in the work and life, strengthen communication with colleagues .Secondly, the organizational system has a greater impact on the satisfaction of cross-border e-commerce talents. The company can implement an attractive equity incentive system to provide protection for long-term retention of outstanding talents. Solve the problems that employees really care about and ensure that cross-border e-commerce companies can achieve good 
career development within the enterprise.

Moreover, in terms of personal factors, cross-border e-commerce merchants are most concerned about the current job promotion and the challenge of work. It is recommended that enterprises be selected and promoted according to the actual ability of talents. Finally, although the results of the study show that the regional factors have relatively little impact on the satisfaction of cross-border electricity merchants, this may be due to the relatively low level of economic development in Henan's own region, so that talents do not pay full attention to regional factors.

\section{References}

[1] Chonghuai, Niu, Yongsheng, Zhang, 2009. Analysis of the gathering environment and aggregation effect of science and technology talents--Analysis of the influence of market environment on the aggregation effect of science and technology talents, Journal of Taiyuan University of Technology(Social Science Edition).(1), pp.10 -12.

[2] Honglin, Guo, Feng, Qi, Fan, Wang, 2016. Research on Talent Flow of Higher Education in China and Its Influencing Factors, Education Research of Tsinghua University.37(01), pp. 69-77.

[3] Jianmin, Sun, Hong, Jiang, 2010. An Empirical Analysis of Job Satisfaction of Science and Technology Personnel in China, Science \& Technology Progress and Policy. 27(4), pp.142-146.

[4] Jianqiang, Wang, 2005.Design of evaluation index system for regional talent competitiveness, Chinese Talents. (15), pp.26-27.

[5] Jianyue, Ji, Yanbin, Zhu, 2008. Research on the Motivation of Science and Technology Talents Flow in China Based on Panel Data, Population and Economy. (5), pp.32-37.

[6] Jing, Guo, Xinmin, Yuan, 2018. Research on the Incentive Satisfaction of Creative Talents, Times Finance. (1), pp.224-226.

[7] Jun, Liu, Chenyao, Qu, Haochang, Yang, 2017. Factors Affecting the Agglomeration of Overseas High-end Talents_Based on the Analysis of Introducing Talents in the "Thousands of Young People", Yuejiang Journal. 9(04), pp.76 -85+146-147.

[8] Qingxiong, Weng, Shuchun, Yang, Weilin, Cao, 2014. The Influence of Regional Environment on Talent Commitment and Roots Willingness, Research Management. 35(06), pp.154-160.

[9] Shihong, Wei, 2017. Discussion on the Incentive Mechanism of Employees in Large E-Commerce Enterprises_-Taking Beijing FKCP Technology Co., Ltd. as an Example, Knowledge Economy. (24), pp.72+74.

[10] Soete, L, 2006. The Impact of Technological Innovation on International Trade Patterns:The Evidence Reconsidered, Research Policy. 2(16), pp.101-130.

[11] Wei, Cheng, 2006. Environmental Effects of Talent Gathering and Optimization of Talent Gathering Environment in the Central and Western Regions, Management Modernization. (3), pp.46-48. 